\title{
Multislice spiral computed tomography can independently predict the bronchoscopy results of children with bronchitis (pneumonia) suspected caused by bronchial foreign bodies
}

\author{
Zhiyong Guo", Liang Li", Bo Cao", Guangping Liu \\ Department of Otorhinolaryngology, Tianjin Children's Hospital, Tianjin University Children's Hospital, Tianjin, China \\ Contributions: (I) Conception and design: L Li; (II) Administrative support: G Liu; (III) Provision of study materials or patients: Z Guo; (IV) \\ Collection and assembly of data: B Cao; (V) Data analysis and interpretation: L Li; (VI) Manuscript writing: All authors; (VII) Final approval of \\ manuscript: All authors. \\ \#These authors contributed equally to this work. \\ Correspondence to: Prof. Zhiyong Guo. Department of Otorhinolaryngology, Tianjin Children's Hospital, Tianjin University Children's Hospital, \\ Tianjin 300074, China. Email: zhiyongguo@live.cn.
}

Background: Multislice spiral computed tomography (MSCT) playsa vital role in the diagnosis of bronchial foreign bodies in children. Bronchitis (pneumonia) can be caused by bronchial foreign bodies in children, which need to be diagnosed and treated by bronchoscopy. To understand the application of MSCT in children with bronchitis (pneumonia) suspected to be caused by bronchial foreign bodies, the clinical data of 162 children were analyzed retrospectively.

Methods: The clinical data of 162 children with bronchitis (pneumonia) suspected to be caused by bronchial foreign bodies were collected, including sex, age, course of the disease, auscultation, chest X-ray, MSCT, bronchoscopy, among many others. Univariate logistic regression analysis analyzed the above other items, taking the finding of foreign bodies in bronchoscopy as the outcome index. The key variables of univariate analysis are included in multivariate logistic regression analysis to determine the independent influencing factors of bronchoscopy results.

Results: Among the 162 patients, $70.4 \%$ were male, with the largest proportion of children aged $1-2$ years $(55.6 \%)$. The course of the disease of 98 cases (60.4\%) was over14 days. A total of 111 cases (68.5\%) showed positive auscultation, 110 cases (67.9\%) showed positive chest fluoroscopy, 155 cases $(95.7 \%)$ showed bronchial foreign bodies with MSCT, and the foreign bodies of 140 cases (86.4\%) were removed by bronchoscopy. Univariate analysis showed that the course of the disease, chest auscultation, and MSCT were all correlated with the results of bronchoscopy. However, multivariate analysis showed, after adjusting the two factors of chest auscultation and chest fluoroscopy, the course of the disease ( $\mathrm{OR}=6.01,2.36-15.29$, $\mathrm{P}<0.001)$ and MSCT $(\mathrm{OR}=95.64,5.62-1,628.40, \mathrm{P}<0.002)$ could still independently predict the results of bronchoscopy.

Conclusions: MSCT can independently predict the results of bronchoscopy in children with bronchitis(pneumonia) suspected to be caused by bronchial foreign bodies.

Keywords: Children; bronchial foreign body; multislice spiral computed tomography (MSCT); bronchoscopy

Submitted Aug 14, 2020. Accepted for publication Sep 29, 2020.

doi: $10.21037 /$ tp-20-300

View this article at: http://dx.doi.org/10.21037/tp-20-300 


\section{Introduction}

Foreign objects cause children's bronchial foreign bodies by entering the human bronchial tubes. It is a typical emergency among children and can cause potentially fatal sequelae (1). When the diagnosis is precise, timely bronchoscopy and foreign body removal are the most common treatment methods for children with bronchial foreign bodies (2). However, in daily clinical practice, many bronchial foreign bodies in children have not been diagnosed in time. The delayed diagnosis of bronchial foreign bodies in children is related to pulmonary complications, including pneumonia and bronchiectasis (3). Childhood bronchial pneumonia is the most common disease of the children's respiratory system, and most of them are community-acquired. When it appears as a complication of a bronchial foreign body, the treatment process is often not straightforward. Because of insufficient cognitive ability and inadequate supervision, the history of inhalation of foreign bodies in children is not straightforward to determine (4). Therefore, when we receive pneumonia caused by a suspected bronchial foreign body, we must promptly assess whether the respiratory tract is unobstructed, and perform a bronchoscopy to remove the foreign body as soon as the diagnosis is precise.

Multislice spiral computed tomography (MSCT) can clearly display the morphology of the bronchus at all levels. Through three-dimensional reconstruction, you can check whether the lumen of the bronchus is unobstructed, and it can predict the results of bronchoscopy very accurately. Studies have shown the sensitivity of MSCT to bronchial foreign bodies can reach $95.5 \%$ (4). The virtual bronchoscopy technology with MSCT is the only imaging method that can guarantee $99.9 \%$ of foreign bodies (5). To improve the safety of surgical procedures, Ozdemir recommends that rigid bronchoscopy for pediatric patients with bronchial foreign bodies should be assisted by an endoscope to allow more effective visualization of the distal bronchus and foreign bodies (6). Carlens retrospectively analyzed the data of bronchoscopy in 522 children aged from 0 to 17 years old. It was found that hypoxemia was the most common intraoperative complication, and fever and transient oxygen dependence were the most common postoperative complications (7). To understand the application of MSCT in children with bronchitis (pneumonia) suspected to be caused by foreign bodies in the bronchial, we retrospectively analyzed the clinical data of 162 related children. We present the following article in accordance with the STROBE reporting checklist (available at http://dx. doi. org/10. 21037/tp-20-300).

\section{Methods}

\section{Patients}

One hundred sixty-two patients with bronchitis(pneumonia) suspected of being caused by foreign bodies in the bronchial were selected as the object of study. All subjects were diagnosed with bronchitis (pneumonia) by symptoms, auscultation and plain chest $\mathrm{X}$-ray examination, the nursing family members could not provide a clear history of foreign body inhalation, and the vital signs of the children were stable, and meet one of the following inclusion criteria: (I) severe atelectasis and emphysema at the time of diagnosis; (II) symptoms and imaging recovery are not apparent after a week of routine treatment; (III) repeated attacks after improvement of bronchitis(pneumonia) in the same position. Patients who met one of the following conditions will be excluded from this study: (I) with immunodeficiency disease; (II) with bronchopulmonary malformation; (III) caregiver family members provide a clear history of foreign body inhalation.

The study was approved by the Ethics Committee of Tianjin Children's Hospital (No. L2020-31) and written informed consent was obtained from all patients. All procedures performed in this study involving human participants were in accordance with the Declaration of Helsinki (as revised in 2013).

\section{Treatments}

After medical history collection and physical examination, all hospitalized patients with bronchitis (pneumonia) were routinely treated with the empirical anti-infective treatment of antibiotics, expectorant treatment, aerosol inhalation, and other symptomatic support treatment. Patients with bronchitis (pneumonia) following the above characteristics were examined by chest fluoroscopy and MSCT to test whether bronchitis (pneumonia) was secondary to foreign bodies in the bronchial. After a precise diagnosis, bronchoscopy was performed. Chest auscultation found that unilateral respiratory sounds decreased and wheezing was positive; Chest fluoroscopy found that mediastinal contradictory movement was positive; MSCT found local obstruction or bronchial stenosis was positive; bronchoscopy found that exogenous foreign bodies were positive. 
Table1 Patient clinical characteristics

\begin{tabular}{|c|c|}
\hline Characteristics & Total n, (\%) \\
\hline Total & $162(100.0)$ \\
\hline \multicolumn{2}{|l|}{ Sex } \\
\hline Male & $114(70.4)$ \\
\hline Female & $48(29.6)$ \\
\hline \multicolumn{2}{|l|}{ Age, years old } \\
\hline$\leq 1$ & $8(4.9)$ \\
\hline $1-2$ & $90(55.6)$ \\
\hline $2-3$ & $39(24.1)$ \\
\hline$\geq 3$ & $25(15.4)$ \\
\hline \multicolumn{2}{|c|}{ The course of the disease, days } \\
\hline$\leq 7$ & $9(5.6)$ \\
\hline $7-14$ & $55(34.0)$ \\
\hline$\geq 14$ & $98(60.4)$ \\
\hline \multicolumn{2}{|c|}{ Chest auscultation } \\
\hline Negative & $51(31.5)$ \\
\hline Positive & $111(68.5)$ \\
\hline \multicolumn{2}{|c|}{ Chest fluoroscopy } \\
\hline Negative & $52(32.1)$ \\
\hline Positive & $110(67.9)$ \\
\hline \multicolumn{2}{|l|}{ MSCT } \\
\hline Negative & $7(4.3)$ \\
\hline Positive & $155(95.7)$ \\
\hline \multicolumn{2}{|l|}{ Bronchoscopy } \\
\hline Negative & $22(13.6)$ \\
\hline Positive & $140(86.4)$ \\
\hline
\end{tabular}

MSCT, multislice spiral computed tomography.

\section{MSCT}

The 16 slice spiral CT (Siemens, Germany) was used for scanning. Cooperative children were instructed to hold their breath for $5 \mathrm{~s}-7 \mathrm{~s}$, and uncooperative children were sedated with $10 \%$ chloral hydrate to calm their breathing. A thin layer volume scan was performed from the beginning of the trachea to the top of the right diaphragm, and a $0.75 \mathrm{~mm}$ thickness detector was used to collect data. After scanning, $20 \mathrm{~mm}$ slice thickness and $0.05 \mathrm{~mm}$ slice spacing were selected for later reconstruction. The SYNGO system was used for post-image processing, mainly using multiplanar reformation (MPR), curve multi-planar reformation (CMPR), minimum intensity projective (MinIP), volume rendering technique (VRT), CT virtual endoscopy (CTVE), shaded surface display (SSD) and other reconstruction methods.

\section{Bronchoscopy}

The rigid bronchoscope produced by the Storz company in Germany was used for examination (fiberoptic bronchoscope and endoscope were used together). After general anesthesia, the corresponding bronchoscope was placed through the mouth, and the glottis, trachea, carina, bilateral bronchus, lobar bronchus and the orifice of each segmental bronchus were examined sequentially. In principle, first, check the healthy side, and then check the affected side, focus on the suspicious part of the observation. If a foreign body is found, then try to remove it.

\section{Statistical method}

Sex, chest auscultation, chest fluoroscopy, MSCT, and bronchoscopy were the classified variables, while age and course of disease were continuous variables. Taking whether bronchoscopy found the foreign bodies as the outcome index, univariate logistic regression analysis analyzed the other items, and the critical variables of univariate analysis were included in multivariate logistic regression analysis.

\section{Results}

\section{Patient clinical characteristics}

As shown in Table 1,70.4\% of the 162patients were male; children aged 1-2 years accounted for the most substantial proportion, accounting for $55.6 \%$; Most of the children $(60.4 \%)$ whose course of the disease was over 14 days; 111 cases $(68.5 \%)$ had positive chest auscultation, 110 cases $(67.9 \%)$ showed positive chest fluoroscopy, 155 cases (95.7\%) showed bronchial foreign bodies with MSCT, and the foreign bodies of 140 cases $(86.4 \%)$ were removed by bronchoscopy.

\section{Results of bronchoscopy}

As shown in Table 2, among the 162 patients, foreign bodies were located in left bronchi in 69 cases, right bronchi in 
Table 2 Results of bronchoscopy in 162 children

\begin{tabular}{lc}
\hline Variable & Total $\mathrm{n},(\%)$ \\
\hline Location of foreign bodies & $162(100.0)$ \\
Total & $69(42.6)$ \\
Left bronchus & $62(38.3)$ \\
Right bronchus & $9(5.6)$ \\
Bilateral bronchus & $22(13.5)$ \\
No foreign body & \\
Type of foreign bodies & $140(100.0)$ \\
Total & $107(76.4)$ \\
Vegetative foreign bodies & $15(10.7)$ \\
Chemical foreign bodies & $12(8.6)$ \\
Animal foreign bodies & $6(4.3)$ \\
Mineral foreign bodies &
\end{tabular}

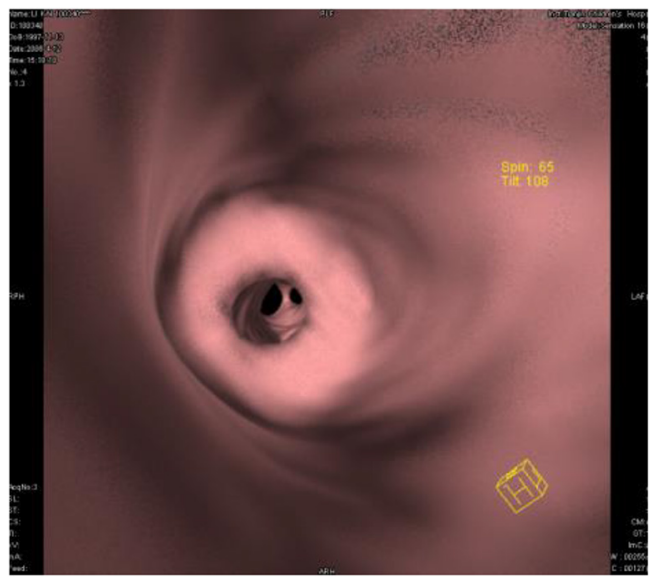

Figure 1 The foreign body removed by rigid bronchoscope.

62 cases, bilateral bronchi in 9 cases, no exogenous foreign bodies in 22 cases; There were vegetative foreign bodies in 107 cases, chemical foreign bodies in 15 cases, animal foreign bodies in 12 cases and mineral foreign bodies in 6 cases. Figure 1 shows the foreign body removed by rigid bronchoscope.

\section{Results of MSCT}

As shown in Table 3, MSCT showed a partial obstruction in 124 cases, bronchial stenosis in 31 cases, no signs of foreign bodies in 7 cases, MSCT found complications: emphysema in 95 cases, atelectasis in 68 cases, mediastinal
Table 3 Results of MSCT in 162 children

\begin{tabular}{lc}
\hline Variable & Total $\mathrm{n},(\%)$ \\
\hline MSCT & $162(100.0)$ \\
Total & $124(76.5)$ \\
Partial obstruction & $31(19.2)$ \\
Bronchial stenosis & $7(4.3)$ \\
No sign of a foreign bodies & \\
Complications & $162(100.0)$ \\
Total & $95(58.6)$ \\
Emphysema & $68(42.0)$ \\
Atelectasis & $65(40.1)$ \\
Mediastinal shift & $16(9.9)$ \\
Pleural effusion &
\end{tabular}

MSCT, multislice spiral computed tomography.

shift in 65 cases, pleural effusion in 16 cases. Figure 2 shows that CTVE can clearly show the foreign body and its incarcerated site.

\section{Univariate and multivariate logistic regression analysis}

As shown in Table 4, univariate analysis showed that the course of the disease, auscultation, and MSCT were all correlated with the results of bronchoscopy, while multivariate analysis showed after adjusting the two factors of auscultation and chest $\mathrm{X}$-ray, the course of the disease $(\mathrm{OR}=6.01,2.36-15.29, \mathrm{P}<0.001)$ and MSCT $(\mathrm{OR}=95.64$, $5.62-1,628.40, \mathrm{P}<0.002)$ could still independently predict the results of bronchoscopy.

\section{Discussion}

A bronchial foreign body is the most common emergency in otorhinolaryngology in children. The diagnosis depends on the history of foreign body inhalation, pulmonary auscultation, and chest fluoroscopy. In the cases with a short course of disease, clear history of foreign body inhalation, lung auscultation to the asymmetry of breathing sound on both sides (one side reduced), and typical mediastinal swing can be identified by chest fluoroscopy, and it is easy to diagnose. Timely bronchoscopy and removal of a foreign body can save the child from danger. However, in clinical work, family members cannot provide or explicitly deny the history of foreign body inhalation, and patients 
with bronchial foreign bodies with pneumonia as the first manifestation will be delayed in diagnosis and treatment, which poses a severe threat to the physical health of children and the psychological status of their families.

Bronchoscopy is the gold standard for the diagnosis of bronchial foreign bodies in children, but the negative rate of bronchoscopy is very high, which brings unnecessary risks and costs of surgery and anesthesia to patients. MSCT has high sensitivity and specificity for bronchial foreign bodies. Selective application of MSCT in the clinical nursing program of children with suspected foreign body inhalation can significantly reduce the negative rate of bronchoscopy, thus reducing the operational risk and cost (8).

Although many studies have confirmed MSCT can accurately diagnose bronchial foreign bodies (9-12).

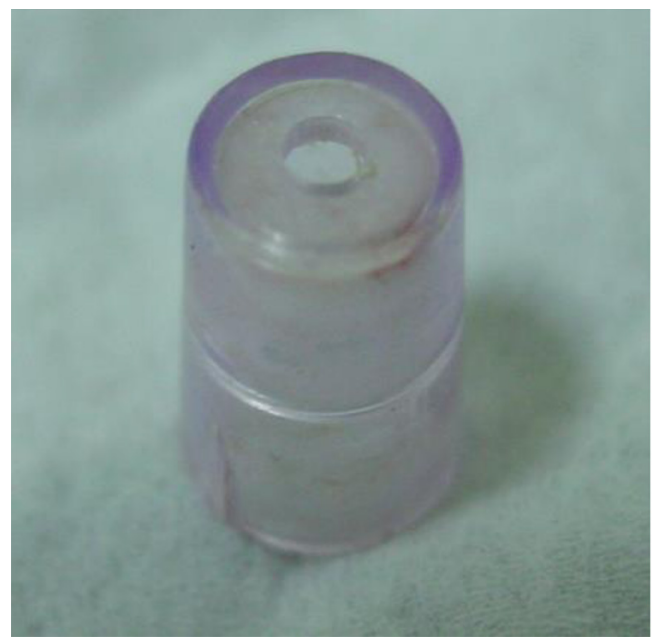

Figure 2 CTVE clearly shows the foreign body and its incarcerated site. CTVE, CT virtual endoscope.
However, because it belongs to the radiological examination, it cannot be routinely and widely used in this particular group of pediatrics. We usually use MSCT in the diagnosis of bronchial foreign bodies only when the routine diagnostic indicators are atypical. Therefore, we selected 162 patients with bronchitis (pneumonia) suspected of being caused by foreign bodies in the bronchial, and underwent MSCT and bronchoscopy. We found that bronchial foreign bodies were common in bronchitis (pneumonia) patients whose care family members could not accurately provide a history of foreign body inhalation, and routine diagnostic indicators of tracheal foreign bodies could not give satisfactory diagnostic results in the course of the disease. However, MSCT could independently predict the results of bronchoscopy.

Hajnal's study, showed that the positive rate of chest auscultation in patients with bronchial foreign bodies with a clear history of foreign body inhalation was $89.5 \%$, while chest fluoroscopy was only $21.1 \%$. And $33.7 \%$ of the patients showed negative results of bronchoscopy. The complication rate of patients with a prolonged course of the disease was significantly higher than acute cases. Therefore, they concluded that rigid bronchoscopy could be performed as long as the history of foreign body inhalation is clear, the symptoms (cough, asphyxia) are typical, or the chest auscultation is positive (13). We also found there was a significant correlation between chest auscultation and a bronchoscopy in univariate analysis $(\mathrm{P}=0.015)$, which was like the above results. Our study selected children with suspected bronchial foreign bodies who could not supply a history of foreign body inhalation, so the other data were inconsistent. Our study precisely makes up for the deficiency of this study. In patients with an uncertain history of foreign body inhalation, MSCT can predict

Table 4 Univariate and multivariate logistic regression analysis for predicting bronchoscopy results

\begin{tabular}{|c|c|c|c|c|c|c|}
\hline Variables & \multicolumn{3}{|c|}{ Univariate } & \multicolumn{3}{|c|}{ Multivariate } \\
\hline Sex & 1.51 & $0.52-4.35$ & 0.448 & & & \\
\hline Age & 1.09 & $0.62-1.90$ & 0.777 & & & \\
\hline The course of the disease & 5.73 & $2.60-12.64$ & $<0.001$ & 6.01 & $2.36-15.29$ & $<0.001$ \\
\hline Chest fluoroscopy & 0.60 & $0.21-1.73$ & 0.345 & 0.20 & $0.04-1.16$ & 0.074 \\
\hline MSCT & 52.13 & $5.90-460.80$ & $<0.001$ & 95.64 & $5.62-1,628.40$ & 0.002 \\
\hline
\end{tabular}

MSCT, multislice spiral computed tomography. 
the results of bronchoscopy and improve the positive rate of bronchoscopy. Our study also suggests we should pay attention to the importance of physical examination (chest auscultation) in clinical work.

Our study also has the following limitations. One, this study, is a retrospective study, and some selection biases are inevitable. Two, this study is a single-center study with a small sample size. Three, our study included fewer indicators. Therefore, in the following clinical work, we must further increase the evaluation indicators, expand the sample size, and conduct multi-center and prospective studies to achieve more reliable research conclusions.

\section{Conclusions}

According to our results, MSCT can independently predict the results of bronchoscopy in children with bronchitis (pneumonia) suspected to be caused by bronchial foreign bodies. Bronchitis (pneumonia) with a long history, especially those with inadequate response to routine treatment, should be examined by MSCT in time, and bronchoscopy and treatment should be performed as soon as possible after definite diagnosis.

\section{Acknowledgments}

Funding: None.

\section{Footnote}

Reporting Checklist: The authors have completed the STROBE reporting checklist. Available at http://dx.doi. org/10.21037/tp-20-300

Data Sharing Statement: Available at http://dx. doi. org/10.21037/tp-20-300

Conflicts of Interest: All authors have completed the ICMJE uniform disclosure form (available at http://dx. doi. org/10. 21037/tp-20-300). The authors have no conflicts of interest to declare.

Ethical Statement: The authors are accountable for all aspects of the work in ensuring that questions related to the accuracy or integrity of any part of the work are appropriately investigated and resolved. The study was approved by the Ethics Committee of Tianjin Children's Hospital (No. L2020-31) and written informed consent was obtained from all patients. All procedures performed in this study involving human participants were in accordance with the Declaration of Helsinki (as revised in 2013).

Open Access Statement: This is an Open Access article distributed in accordance with the Creative Commons Attribution-NonCommercial-NoDerivs 4.0 International License (CC BY-NC-ND 4.0), which permits the noncommercial replication and distribution of the article with the strict proviso that no changes or edits are made and the original work is properly cited (including links to both the formal publication through the relevant DOI and the license). See: https://creativecommons.org/licenses/by-nc-nd/4.0/.

\section{References}

1. Baharloo F, Veyckemans F, Francis C, et al. Tracheobronchial foreign bodies: presentation and management in children and adults. Chest 1999;115:1357-62.

2. Oncel M, Sunam GS, Ceran S. Tracheobronchial aspiration of foreign bodies and rigid bronchoscopy in children. Pediatr Int 2012;54:532-5.

3. Wu Y, Dai J, Wang G, et al. Delayed diagnosis and surgical treatment of bronchial foreign body in children. J Pediatr Surg 2019:S0022-3468(19)30787-0.

4. Shen J, Huang L, Hao C. Value of MSCT for diagnosis of tracheobronchial foreign body aspiration in children: 5-year retrospective study. Pediatr Int 2020. [Epub ahead of print].

5. Ullal A, Mundra RK, Gupta Y, et al. Virtual Bronchoscopy: Highly Sensitive Time and Life Saving Investigation in the Diagnosis of Foreign Body Aspiration-Our Experience. Indian J Otolaryngol Head Neck Surg 2019;71:378-83.

6. Ozdemir S, Surmelioglu O, Tarkan O, et al. The Utility of Endoscope-Assisted Rigid Bronchoscopy in Pediatric Airway Foreign Body Removals. J Craniofac Surg 2020;31:e217-9.

7. Carlens J, Fuge J, Price T, et al. Complications and risk factors in pediatric bronchoscopy in a tertiary pediatric respiratory center. Pediatr Pulmonol 2018;53:619-27.

8. Ahmed OG, Guillerman RP, Giannoni CM. Protocol incorporating airway CT decreases negative bronchoscopy rates for suspected foreign bodies in pediatric patients. Int J Pediatr Otorhinolaryngol 2018;109:133-7.

9. Pitiot V, Grall M, Ploin D, et al. The use of CT-scan in foreign body aspiration in children: A 6 years' experience. Int J Pediatr Otorhinolaryngol 2017;102:169-73. 
10. Bai W, Zhou X, Gao X, et al. Value of chest CT in the diagnosis and management of tracheobronchial foreign bodies. Pediatr Int 2011;53:515-8.

11. Xu Y, Feng RL, Jiang L, et al. Correlative factors for the location of tracheobronchial foreign bodies in infants and children. J Thorac Dis 2018;10:1037-42.

12. Hong WS, Im SA, Kim HL, et al. CT evaluation of airway foreign bodies in children: emphasis on the delayed

Cite this article as: Guo Z, Li L, Cao B, Liu G. Multislice spiral computed tomography can independently predict the bronchoscopy results of children with bronchitis (pneumonia) suspected caused by bronchial foreign bodies. Transl Pediatr 2020;9(5):662-668. doi: 10.21037/tp-20-300 diagnosis and differentiation from airway mucus plugs. Jpn J Radiol 2013;31:31-8.

13. Hajnal D, Kovacs T. Foreign body aspiration of the lower airways in children - diagnosis in clinical practice. Orvosi Hetilap 2018;159:2162-6.

(English Language Editor: J. Chapnick) 